\title{
Questões contemporâneas e desenvolvimento de aplicativos móveis: onde está a conexão?
}

André Luiz França Batista

Walter Antônio Bazzo

\section{Resumo}

Em consequência das discussões sobre estudos Ciência, Tecnologia e Sociedade (CTS) verificou-se a necessidade de entender como promover discussões sobre esses assuntos em uma disciplina de programação de dispositivos móveis. O objetivo deste artigo é mostrar como é possível inserir assuntos pertinentes aos problemas da sociedade em uma disciplina de enfoque altamente técnico. Desse modo o presente trabalho detém um enfoque informativo e torna-se um possível subsídio para auxílio a professores que pretendam estabelecer discussões CTS em suas classes de programação computacional móvel. As sugestões aqui documentadas caracterizam-se como recursos para um provável aprimoramento do pensamento crítico e conduta cidadã dos discentes e para o fomento de discussões e reflexões, entre educadores e futuros profissionais, sobre a realidade vigente, ensejando iminentes mudanças educacionais.

Palavras-chave: Recursos didáticos, Ensino de programação para dispositivos móveis, Questões sociais contemporâneas, Educação tecnológica.

\section{Abstract \\ Contemporary issues and mobile applications development: where is the connection?}

As a result of discussions about studies on Science, Technology and Society (STS) we identified a need to know how to discuss these issues in a discipline of mobile programming. The purpose of this article is to show how we can introduce relevant matters to society's problems in a highly technical approach to discipline. Thus this work has an informative approach and becomes a possible grant to aid the teachers who want to establish STS discussions in your mobile programming classes. Suggestions documented here characterized as resources for a likely improvement of critical thinking and civic conduct of students and for the promotion of discussion and reflection among teachers and future professionals on the current reality, allowing for imminent educational changes.

Keywords: Teaching resources, Teaching mobile programming, Contemporary social issues, Technological education. 


\section{Introdução}

Assim como o uso de smartphones e seus respectivos softwares aplicativos são muito atrativos, o desenvolvimento destes aplicativos pode também fascinar muitos jovens. Podemos afirmar que, não raro, o ensejo de ser iluminado com uma ideia impactante, revolucionária no universo computacional móvel, é motivo para muitos jovens buscarem formação profissional nessa área. O relatório de Brasscom (2014) mostra que o Brasil é o quarto maior mercado de TI e Telecomunicações do mundo, atrás somente dos Estados Unidos, China e Japão. Esse mesmo relatório ainda revela que o Brasil é o quarto maior mercado de Smart Connected Devices (desktops, notebooks, tablets, smartphones) com uma estimativa de 71 milhões de dispositivos vendidos em 2014.

Entretanto, o ensino e a aprendizagem de desenvolvimento de softwares não pode deixar de abordar questões sociais contemporâneas, sobretudo as decorrentes de seu uso, modismos, fluência pouco acrítica e até mesmo vícios ou dependência. Minha preocupação nos últimos anos, como professor de programação, era "dar uma espécie de treinamento descompromissado sobre esses tópicos". Ao iniciar os estudos sobre "Ciência, Tecnologia e Sociedade" (CTS), abriu-se um olhar para esses pontos. Logo surgiu a inquietação: Como abordar as questões contemporâneas em um curso, ou disciplina, de programação de computadores, especificamente programação para dispositivos móveis?

A Tecnologia da Informação (TI) permeia - cada vez mais intensamente - quase todas as atividades humanas, incluindo trabalho, lazer, saúde, educação e comunicação, cabendo aos profissionais dessa área a responsabilidade pelo desenvolvimento de parte ou boa parte de soluções, ferramentas e processos coerentes com valores éticos e interesse social, e que também busquem o bem-estar do homem e o avanço tecnológico. Ora, para exercer com competência, plenitude e capacitação essas atribuições, é indispensável que o profissional tenha, pelo menos, realizado os estudos referentes a questões sociais, filosóficas, e éticas, com um bom grau de sistematização e reflexão.

Em síntese, de maneira até reducionista, parece que em uma ponta se encontra a atual tendência de desenvolver aplicativos para smartphones, e em outra - diametralmente oposta situam-se os temas sociais contemporâneos. Como conectar esses polos em bom funcionamento e trabalhar com eles de forma integrada e contextualizada? 


\section{Ponto "A": Tecnologias de informação móvel}

É fácil visualizar o papel essencial que a TI, ou simplesmente Informática, assumiu em nossa sociedade em tempos recentes. Praticamente todas as atividades corriqueiras fazem uso de um ou mais recursos oriundos da TI. A automatização da informação transformou a velocidade com que a informação é criada, gerenciada e recuperada. Pagar uma conta em uma agência bancária ou casa lotérica, fazer uma compra em um supermercado, realizar uma viagem de avião ou qualquer transporte público, são atividades que necessitam de um sistema computacional auxiliando a gestão empresarial. Entretanto, não apenas as empresas são beneficiadas com o uso da Informática. Tais adventos também atingem diretamente as pessoas seja de forma individual ou coletiva (ABES, 2014; BRASSCOM, 2014).

Com o avanço da tecnologia computacional, os dispositivos e seus componentes reduziram de tamanho ao mesmo tempo que expandiram seu poder de processamento. Até então, computadores que ocupavam grandes espaços físicos hoje cabem na palma da mão. Os chamados smartphones, ou telefones inteligentes, são atualmente verdadeiros assistentes pessoais. São dispositivos computacionais, de tamanho reduzido, que desempenham serviços como despertador, bloco de anotações, agenda de contatos (de capacidade praticamente infinita), agenda de compromissos, mini-estação de áudio e vídeo, estúdio de fotografia, localizador geográfico pessoal com atlas mundial possuindo precisão de cinco metros, comunicador instantâneo pessoal de voz e dados, dentre inúmeros e incontáveis outros recursos de uso individual. Em 2 de Fevereiro de 2015, de acordo com estatísticas de AppBrain (2015), a loja virtual de aplicativos do sistema Android contava com 1.525.275 aplicativos disponíveis, enquanto o seu principal concorrente - o sistema iOS - contava com 1.400 .000 aplicações móveis a disposição, conforme Apple (2015).

O desenvolvimento de aplicativos para dispositivos móveis tem atraído muitos entusiastas aos cursos técnicos e superiores em tecnologia da informação. Esse interesse surge devido à crescente expansão desse mercado e a possibilidade de remuneração por meio desses aplicativos. É notável o crescimento vertiginoso do mercado de desenvolvimento de aplicativos móveis. Em 2014, arrecadou uma receita global de 13 bilhões de dólares, com um aumento de 100\% ao ano, sendo a Apple responsável por 67\% desse valor, e o Google pelos 33\% restantes, conforme relatório de AppAnnie (2015). Recentes pesquisas da Gartner (2014) mostram uma previsão de que este mercado alcance US\$77 bilhões em 2017. Em 2013, os usuários consumiram em média cerca de $2 \mathrm{~h} 38 \mathrm{~m}$ por dia em smartphones e tablets, sendo que $86 \%$ desse tempo $(2 \mathrm{~h} 19 \mathrm{~m})$ foi gasto em aplicativos e $14 \%(0 \mathrm{~h} 22 \mathrm{~m})$ acessando sites da internet móvel. Ainda conforme o relatório de Gartner (2014), em 2014 o acesso à internet por dispositivos móveis superou o acesso por desktops (computadores de mesa e notebooks). Esse alto crescimento do consumo de aplicações móveis tem despertado o interesse de diversos setores da sociedade, inclusive governamentais.

DOI: Em andamento. 
Com o objetivo de fomentar a produção de aplicativos nacionais para dispositivos móveis e TVs inteligentes (Smart TVs), o governo brasileiro abriu, por meio do Ministério das Comunicações, no início de Agosto de 2014 um edital que objetivou estimular a criação de aplicações móveis de utilidade pública e "jogos sérios", conforme Brasil (2014). Os investimentos de $R \$ 4,5$ milhões atenderão um total de 50 aplicativos (25 aplicativos e 25 aplicativos jogos). De acordo com o Ministério das Comunicações, "o desenvolvimento de jogos e aplicativos não tem acompanhado a demanda do mercado brasileiro - que é o quarto consumidor desse segmento, movimentando R\$ 850 milhões por ano". O concurso chamado INOVApps faz parte da Política Nacional para Conteúdos Digitais Criativos do Ministério das Comunicações.

Paralelo aos incentivos, por meio de editais e concursos, podemos perceber um aumento na abertura de cursos de TI. A crescente oferta destes cursos visa acompanhar o aumento da demanda de profissionais desta área no Brasil conforme indicam muitas pesquisas. Um estudo feito pela Associação Brasileira de Empresas de Software (ABES) em 2014, mostrou que o Brasil carece de mais profissionais de TI. Este estudo revela que os profissionais de $\mathrm{TI}$ do Brasil encontram um mercado de trabalho em crescimento e com baixa competição qualificada para vagas em aberto. Os pesquisadores ainda alertam para um agravamento na carência por profissionais de tecnologia no país até 2017. De acordo com a pesquisa da ABES (2014), há hoje, no Brasil, uma carência de aproximadamente 40 mil profissionais da área de TI. Esse número pode crescer para até 117 mil vagas abertas em 2017, sem que os empregadores consigam contratar pessoas com qualificação necessária para preenchê-las.

A formação destes profissionais para preencher essas vagas em aberto deve ser repensada, de modo a incluir, no processo formativo, os temas CTS. Sendo assim, a expectativa é formar cidadãos capacitados a participarem de forma crítica e consciente no processo de tomada de decisões e nos debates sociais, pessoas preocupadas com as implicações sociais inerentes ao desenvolvimento de inovações científicas e tecnológicas (DA SILVA, 2014, p. 130).

\section{Ponto “B”: Temas sociais contemporâneos}

Os cursos técnicos e superiores em Tecnologia da Informação abordam em seus currículos os conteúdos técnicos da Computação com pequenos enxertos de disciplinas de cunho humanístico e/ou social. No ano de 2012 o Ministério da Educação/Conselho Nacional de Educação emitiu um parecer - CNE/CES 136/2012 - sobre as Diretrizes Curriculares Nacionais para os cursos de bacharelado e licenciaturas em Computação (BRASIL, 2012). Esse documento sugere a adoção de disciplinas de caráter humanístico e social, tais como: Computação e sociedade; Filosofia; Meio ambiente; Relações humanas de trabalho; Impactos sociais da tecnologia de software. A inserção de debates sobre esses conteúdos nos cursos de TI, não 
apenas os cursos superiores mas também em cursos de nível técnico, visa capacitar os futuros profissionais a exercerem as suas atribuições com competência.

Em um interessante trabalho, Côrrea \& Araújo (2014) apresentam a percepção de alunos e professores de uma instituição pública federal de educação profissional técnica de nível médio sobre temas CTS. O trabalho destes autores é relevante para a nossa discussão, haja vista que nosso ponto é a inserção destes temas CTS em cursos de educação profissional e tecnológica. A opinião de Côrrea \& Araújo (2014), que também é a nossa visão, versa que:

[...] precisamos dispor, então, na medida necessária, de conhecimentos em ciência e tecnologia, mas também sobre ciência e tecnologia e compor uma sociedade crítica e reflexiva, atenta às situações e dilemas decorrentes das relações entre C\&T e atividades sociais, econômicas e políticas, bem como aos riscos gerados pelas aplicações técnico-científicas (CÔRREA, ARAÚJO, 2014, p. 15).

Em suma, a perspectiva de Côrrea \& Araújo (2014), defende a promoção, em sala de aula, de discussões no sentido de elaborar novas concepções sobre ciência, tecnologia e sociedade, no intuito de contribuir para minimizar visões inadequadas aos desafios impostos para a educação científica nos nossos dias.

Conforme Bazzo et al. (2014), entrar em uma sala de aula para tratar das relações CTS parece cada dia mais desafiador.

Mexer nas bases da educação, primordialmente a tecnológica, é de extrema complexidade. Mas, na lida diária do autor em perscrutar os problemas do mundo, sentiu a urgência de algumas sérias modificações. É necessário sair da posição cômoda de uma formação puramente técnica, de um treinamento técnico descompromissado com as questões sociais. É preciso abordar os assuntos referentes aos conteúdos sociais (BAZZO ET AL., 2014, p. 39).

O professor e tudo aquilo que ele ensina fazem parte do mesmo mundo que os alunos vivem. É evidente a necessidade de um despertar para outras dimensões na educação tecnológica, dimensões que discursam sobre as atuais questões sociais.

Objeto dos estudos CTS, a inserção dessas questões contemporâneas em cursos da área de TI, de acordo com Bazzo (2012), tem como objetivo promover uma educação que busca valores humanos indispensáveis para a efetivação de uma sociedade mais justa e igualitária. É preciso haver uma harmonia entre a área humana e a científico-tecnológica. Porém, segundo Bazzo (2012), só chegaremos a essa tal harmonia quando unirmos essas áreas e, ao mesmo tempo, tivermos clareza quanto à importância do "ser" em relação ao "ter". Enquanto isso não ocorrer, talvez não passe de devaneio qualquer outra tentativa de imprimir uma reflexão mais profunda acerca da relação harmônica entre ciência, tecnologia e sociedade.

R. B. E. C. T., vol 8, núm. 4, set-dez.2015 ISSN - 1982-873X

DOI: Em andamento. 
Eduardo Galeano, autor uruguaio, em seu livro "De pernas pro ar - a escola do mundo ao avesso" fala sobre diversas questões sociais contemporâneas. $O$ autor traz um conjunto de fatos, eventos históricos e jornalísticos que comprovam a inversão do mundo em que vivemos. Nesta escola do mundo ao avesso, os discentes acompanham cursos básicos de injustiça, de racismo e machismo, assistem a cátedras sobre medo, seminários de ética, aulas de impunidade, todas elaboradas por meio da pedagogia da solidão. Embora seja uma obra datada de 1998, a mesma permanece como um dossiê da dura, estranha e injusta realidade na qual todos vivemos.

Galeano (2009) aborda questões ambientais mostrando como as grandes empresas, sediadas em países de alto poder hegemônico, destroem a natureza em prol dos altos lucros, exploram países por meio do uso de sua mão de obra barata e pouco poder de contestação. 0 autor também acolhe dados e fatos históricos sobre a violência urbana, sobre a violência no trânsito e em outras áreas. Galeano também versa sobre a sociedade do consumo e como o "ter" tem se sobressaído sobre o "ser". São assuntos como esses aflorados no livro citado que devem ser discutidos nos cursos de TI, em especial nas disciplinas de programação de aplicações móveis que é o cerne deste artigo.

\section{Conexão e articulação entre ponto "A" e ponto "B"}

É de essencial importância a questão da inserção de temas CTS e em cursos de instituições de formação profissional e tecnológica. Oliveira et al. (2012) buscam, em seu trabalho, identificar se existe, nestas instituições, a preocupação com implicações sociais decorrentes da relação entre ciência e tecnologia. Partindo disso, os autores discorrem sobre como se concebe o desenvolvimento do conhecimento vinculado ao ensino técnico e tecnológico, considerando suas implicações sociais. Os pesquisadores ainda complementam que tais instituições são "constituídas como espaços públicos de produção e difusão do conhecimento, e deve ser um canal para levantar esse tipo de discussão na formação de sujeitos" (OLIVEIRA et al., 2012, p. 10).

Eichler \& Del Pino (2014) desenvolveram um trabalho onde a relação entre temas CTS e tecnologias digitais é bem articulada. Uma importante perspectiva deste trabalho refere-se as relevantes contribuições que a abordagem CTS tem na educação científica. Os autores apresentaram esses apoios como:

i) o nível de abstração pode ser reduzido; ii) o conhecimento pode ser reorganizado ('repackaged', no original), pelos professores; iii) o conhecimento pode ser reconstruído, pelos alunos; $e$ iv) o conhecimento pode ser contextualizado. (EICHLER, DEL PINO, 2014, p. 121). 
Segundo os autores, é possível declarar que para a solução de questões sociais e ambientais contemporâneas é preciso uma geração de cidadãos formados política e cientificamente que não se contentem com o papel de simples críticos passivos.

Considerando a experiência pregressa no ensino da especificidade junto aos desafios e complexidade das questões CTS afins, apresentaremos algumas sugestões que nos parecem oportunas e pertinentes sobre como realizar a conexão entre o ensino de desenvolvimento de aplicativos móveis e tópicos sociais atuais.

O racismo é um assunto muito presente em nossa sociedade mas infelizmente pouco debatido nas escolas, e possui abordagem zero em cursos/disciplinas de desenvolvimento de aplicativos. Os casos mais mencionados de racismo atualmente no Brasil referem-se aqueles praticados em partidas de futebol. É possível planejar uma sequência de aulas que integrem desenvolvimento de aplicativos e racismo. Para abordar este assunto, o professor pode propor aos alunos o desenvolvimento um aplicativo no qual o usuário efetua denúncias anônimas de atos racistas. O aplicativo poderá ser utilizado dentro dos estádios de futebol, informando anonimamente às autoridades competentes a localização do ato racista. Para auxiliar os discentes no processo educacional, o professor deve indicar leituras, vídeos e outros materiais que debatem o assunto com uma visão mais atual. A obra de Galeano (2009) é um excelente material que pode ser utilizado nesse tipo de projeto. Neste livro, o capítulo "Curso básico de racismo e machismo" traz fatos históricos e atuais que podem enriquecer e fornecer subsídios valiosos para que os alunos possam se aprofundar um pouco mais sobre desigualdades e discriminação racial.

A temática violência tem muitas vertentes, uma delas é aquela cometida contra crianças e mulheres. Infelizmente é um fato recorrente em nossa sociedade. Com o objetivo de discutir esse tópico, o docente pode sugerir a condução de um projeto no qual os alunos desenvolveriam um aplicativo para auxiliar na repressão desse ato. $O$ aplicativo disporia das principais características de cada tipo de violência, baseada nas quais ele retornaria o telefone e o endereço dos lugares mais próximos da localização do usuário, onde se pode buscar ajuda. Como pequeno exemplo, a Tabela 1 apresenta uma sugestão inicial.

Tabela 1 - Sugestão inicial para aplicativo contra violência.

Natureza da violência

\begin{tabular}{ll}
\hline & Delegacias Especiais da Mulher \\
Agressão contra mulheres & Centros de Referência de Atenção à \\
& Mulher \\
& Serviços de Atenção Integral à Mulher \\
\hline \multirow{2}{*}{ Agressão contra crianças e adolescentes } & Conselhos Tutelares \\
& Delegacias Especializadas em Crimes \\
\hline
\end{tabular}

R. B. E. C. T., vol 8, núm. 4, set-dez.2015 ISSN - 1982-873X

DOI: Em andamento. 


\begin{tabular}{ll}
\hline contra Crianças e Adolescentes \\
Disque Direitos Humanos (Ligue 100) \\
123 Alô - A voz da criança e do \\
adolescente \\
\hline Outras naturezas de violência & Delegacias comuns \\
& Polícia Militar (Ligue 190) \\
\hline
\end{tabular}

As informações contidas na Tabela 1 podem ser encontradas em cartilhas especializadas nesse assunto. A cartilha Maria da Penha em Ação (produção dos Ministérios Públicos Estaduais), e o site Childhood (Pela Proteção da Infância), disponível em <http://www.childhood.org.br>, são fontes úteis em projetos desta natureza. Entretanto, o professor deve instruir os alunos a buscarem informações sobre esses serviços em suas comunidades locais, em suas cidades, dados como endereço, telefone, e horários de atendimento. Assim, se o professor já ensinou a implementação do recurso de geo-localização (Global Positioning System - GPS), o aplicativo poderá até indicar a distância entre o usuário e estes centro de ajuda. Além disso, tal aplicativo poderia desfrutar da opção de realizar automaticamente a chamada telefônica para o centro de ajuda responsável.

Outra vertente deste tópico remete à violência urbana: assaltos, sequestros, roubos, lamentavelmente cada dia mais frequentes. $O$ educador tem como opção indicar a execução de um projeto para criação de um aplicativo que permite informar e monitorar situações de perigo. Com isso, existe a possibilidade da criação de um sistema de recomendação informando quais são os níveis de violência em diferentes regiões da cidade. Baseado em um sistema de GPS seria possível, inclusive, mapear regiões de risco nas cidades. Por meio do aplicativo o usuário poderia receber e enviar pedidos de socorro silenciosamente. Paralelamente à condução do projeto, o docente utilizaria leituras específicas e materiais complementares que versam sobre a violência em todas as nuances. A Polícia Militar de cada estado tem como prática a elaboração de cartilhas com dicas e informações sobre segurança dos cidadãos. Esse tipo de material informativo é muito útil e pode ser encontrado nos respectivos sites de cada unidade policial estadual, algumas estão presentes até mesmo em redes sociais como Twitter e Facebook.

A questão ambiental também é detentora de muitas linhas, como qualidade do ar e da água, desmatamentos, gestão de resíduos líquidos e sólidos. Uma das propostas que o professor pode sugerir aos seus alunos seria a criação de um aplicativo que indique a localização e a rota de acesso até os postos de coleta de determinados resíduos sólidos, como por exemplo: coleta de óleo de cozinha, coleta de baterias de telefones celulares, e também resíduos recicláveis. Além disso, o aplicativo informará ao usuário onde e como descartar os diferentes tipos de resíduos. Para obter esse tipo de informação, o professor pode apresentar aos alunos a Cartilha de Educação Ambiental - Descarte de Resíduos Sólidos (FIOL, 2015) que esclarece quais são os tipos 
de resíduos e como proceder para o descarte de cada um. Além disso, é importante o professor buscar - juntamente com os alunos - informações sobre o descarte de resíduos em sua comunidade local. Assim, os alunos podem conhecer ainda mais o local, a cidade, onde vivem e os serviços ambientais disponíveis em sua região.

Outro sério problema atual é a escassez de água. O sistema Cantareira é um dos principais sistemas de captação e tratamento de água da grande São Paulo. O nível das represas sofreu forte queda em 2014 principalmente por causa da estiagem registrada no estado de São Paulo e nas cabeceiras das represas. O fornecimento de água para a grande São Paulo está comprometido. A economia de água e energia elétrica é uma prática essencial. Diante desta contextualização, o educador pode propor aos alunos a elaboração de um projeto para a produção de um jogo educativo ambiental retratando boas práticas de conservação da água e energia elétrica. No jogo o usuário/jogador ganha pontos por realizar ações que promovem o uso consciente desse recurso natural. $O$ engajamento que um jogo suscita nos jovens do século XXI é maior do que uma leitura ou até mesmo um filme. A criação de um jogo que possua os elementos corretos de game-design pode tornar-se uma aplicação atrativa e estar presente em smartphones de outras pessoas, além dos próprios discentes. Os elementos de game-design de um jogo de sucesso podem ser encontrados com detalhes na obra de Jesse Schell (SCHELL, 2014). Para subsidiar o tema hídrico, sugerimos o relatório técnico "Cuidando das águas", produzido em conjunto pelas organizações Programa das nações Unidas pelo Meio Ambiente (PNUMA), Agência Nacional das Águas (ANA) e Conselho Empresarial Brasileiro para o Desenvolvimento Sustentável (CEBDS). O relatório PNUMA (2011) traz conhecimentos relevantes acerca dos recursos hídricos, e também sugere soluções para melhoria da qualidade da água, e ações para evitar a sua escassez.

O consumo consciente é um assunto que precisa ser abordado em nossas escolas. Conhecer o produto que estamos comprando é muito importante. Saber se contém elementos tóxicos, nocivos, se afeta o meio ambiente de alguma forma, pode fazer a diferença na hora de realizar uma compra consciente. Em uma sociedade cada vez mais consumista, guiada pela mídia, o educador pode propor a criação de um aplicativo para ser usado em um supermercado. Inicialmente, constrói-se um banco de dados com informações e preços de diversos produtos em diferentes estabelecimentos comerciais. Posteriormente, implementa-se uma função na qual a câmera do aparelho visualiza o código de barras do produto que está sendo comprando, então o aplicativo retorna - a partir do bando de dados - a informação se o preço daquele produto está melhor, ou não, em outros estabelecimentos comerciais. Para servir como guia paralelo à condução deste projeto, o professor pode usar cartilhas e guias do Consumidor Consciente, que podem ser encontradas nos Órgãos de Defesa do Consumidor de cada cidade, pessoalmente ou pela Internet.

Aqui colocamos algumas propostas de como conectar questões sociais modernas às disciplinas - ou cursos - sobre desenvolvimento de aplicativos móveis. Não são propostas 
redentoras, salvadoras, com a pretensão de resgatar o planeta desses problemas. Mas podem emergir como uma orientação, uma janela, para debater com os educandos sobre os problemas humanitários e sociais que enfrentamos atualmente.

\section{Considerações finais}

A emergente tecnologia móvel conquistou um espaço notável em nossa sociedade. Os cursos de TI têm tentado acompanhar essa demanda. Os rumos da educação tecnológica, em especial da TI, são essencialmente tecnicistas com pouca - ou quase nenhuma - abordagem de assuntos relevantes ao contexto social moderno no qual estamos inseridos. Uma mudança de direção é imprescindível.

A abordagem de assuntos socialmente contextualizados por meio da condução de projetos de criação de aplicativos móveis é exposta como uma alternativa para os educadores. O conteúdo apresentado objetiva ser uma centelha para que o professor possa incendiar as ideias e abrir as discussões em torno destes e de outros temas socialmente relevantes.

A mudança de rumos possibilitará a formação de profissionais mais esclarecidos, mais cientes e mais instruídos a respeito do processo civilizatório no qual nós estamos inseridos. Não devemos ser tecnofóbicos. A Informática e seus avanços são evidentes e extremamente relevantes, mas os avanços tecnológicos não podem suprimir - ou até mesmo estar alheios - as questões referentes ao processo civilizatório. A conexão entre esses dois pontos pode e deve existir, precisando ser fortalecida e bem articulada.

\section{Referências}

ABES. Mercado Brasileiro de Software - Panoramas e Tendências. Relatório técnico. Associação Brasileira das Empresas de Software (ABES). 2014. Acesso em 6 de fevereiro de 2015. http://www.abes.org.br.

APPANNIE. App Annie Index 2014 Retrospective: Top app trends of 2014. Relatório técnico. 2015. Disponível em: <http://blog.appannie.com/app-annie-index-retrospective-2014/>. Acesso em 20 de fevereiro de 2015.

APPBRAIN. Number of Android applications. 2015. Disponível em: <http://www.appbrain.com/stats/number-of-android-apps>. Acesso em 20 de fevereiro de 2015.

APPLE, Press Info. App Store rings in 2015 with new records. 2015. Disponível em: $<$ http://www.apple.com/pr/library/2015/01/08App-Store-Rings-in-2015-with-New-

Records.html>. Acesso em 20 de fevereiro de 2015.

BAZZO, W. A.; BAZZO, J. L. dos S.; PEREIRA, L. T. do V. Conversando sobre educação tecnológica. 1a ed. Santa Catarina. Editora UFSC, 2014. 
Cultura científica versus humanística: a cts é o elo? Revista Ibero Americana de Educação (ISNN 1022-6508) número 58 - Janeiro/Abril 2012.

BRASSCOM (2014). Predictions Brazil 2014: Top trends. Relatório técnico. Associação Brasileira das Empresas de Tecnologia da Informação e Comunicação. (BRASSCOM). Disponível em: <http://www.brasscom.org.br/brasscom/Portugues/download.php?cod=567>. Acesso em 16 de fevereiro de 2015.

COMUNICAÇÕES. Ministério das Comunicações. Concurso INOVApps. 2014. Disponível em: <http://www.comunicacoes.gov.br/concurso-inovapps>. Acesso em 6 de fevereiro de 2015.

CORRÊA, A. L. L.; DE ARAÚJO, M. S. T. Aspectos do enfoque CTS no Ensino Profissional Técnico de Nível Médio. Revista Brasileira de Ensino de Ciência e Tecnologia, v. 6, n. 3, 2014.

EICHLER, M. L.; DEL PINO, J. C. Ĵigo: um editor de objetos de aprendizagem de temas de Ciência, Tecnologia e Sociedade (CTS). Revista Brasileira de Ensino de Ciência e Tecnologia, v. 7, n. 1, 2014.

FIOL. Ferrovia Integração Oeste-Leste. Educação Ambiental Descarte de Resíduos. Disponível: <http://www.educamb.com.br/fiol/home.php?pg=10>. Acesso em 22 de fevereiro de 2015.

GALEANO, E. De pernas pro ar - a escola do mundo ao avesso. 1a ed. Editora L\&PM Pocket, 2009.

GARTNER, Inc. Gartner Says By 2017, Mobile Users Will Provide Personalized Data Streams To More Than 100 Apps And Services Every Day. 2014. Disponível em: <http://www.gartner.com/newsroom/id/2654115>. Acesso em 20 de fevereiro de 2015.

MEC. Ministério de Educação e Cultura. Diretrizes Curriculares - Cursos de Graduação. 2012. Disponível em: <http://portal.mec.gov.br/index.php?option=com_content\&id=12991>. Acesso em 6 de fevereiro de 2015.

OLIVEIRA, F. P. Z.; Et al. Os Institutos Federais, a ciência e tecnologia: e a sociedade? Anais do XL Congresso Brasileiro de Educação em Engenharia - COBENGE (ISSN 2175-957X) - Setembro 2012.

PNUMA. Cuidando das águas. PNUMA, ANA, CEBDS. Relatório técnico. 2011. Disponível em: $<$ http://www.pnuma.org.br/publicacoes_detalhar.php?id_publi=89>. Acesso em 23 de fevereiro de 2015.

SCHELL, J. A Arte do Game Design: O livro oficial. Elsevier, 1a ed. 2014.

SILVA, A. C. Uma Possível Associação entre Ciência e Tecnologia no Ensino de Ciências: o exemplo do telefone. Revista Brasileira de Ensino de Ciência e Tecnologia, v. 6, n. 3, 2014.

André Luiz França Batista - Professor de Computação do Instituto Federal do Triângulo Mineiro (IFTM). Doutorando em Educação Científica e Tecnológica (PPGECT) pela UFSC. Mestre em Engenharia de Sistemas pela UFLA (2009). Bacharel em Ciência da Computação pela UFLA (2007). E-mail: andreluiz@iftm.edu.br

DOI: Em andamento. 
Walter Antônio Bazzo - Doutor em Educação e pesquisador em Educação Tecnológica e CTS. Professor do Departamento de Engenharia Mecânica e do Programa de Pós-Graduação em Educação Científica e Tecnológica (PPGECT) da UFSC. Atual coordenador e um dos fundadores do Núcleo de Estudos e Pesquisas em Educação Tecnológica (NEPET).E-mail: walter.bazzo@ufsc.br 